\title{
Aspects regarding skills and education related to Industry 4.0
}

\author{
Felicia Veronica Banciu, ${ }^{1, *}$, and Anamaria Ioana FEIER ${ }^{1}$ \\ ${ }^{1}$ Politehnica University Timişoara, Mechanical Faculty, IMF Department, Bl. Mihai Viteazu No.1, \\ Timişoara, România
}

\begin{abstract}
People is changing. Technology is changing. Economy is changing. Society is changing. Education is changig. In the Industry 4.0 the digitalization and VR, AR, CPS, IoT, ICT, AI assures higher precisions, higher productivity, mass customisation, less waste, and less pollution and contributes to the society change. All the applied and ready to apply technologies receive digital component, as result of the rapid development of information and communication technology. The main objective of the paper is to see in specialized literature what are the skills required by Industry 4.0 (I.4.0), what are the means associated with the concept of Education 4.0 (E.4.0) to obtain them, and to what extent education systems are adapting to these new requirements, which are constantly changing. In addition, it is presented the current situation regarding education perspective and some directions of action, and at the end, a number of conclusions focused on what we could do to all benefit from technological progress in industry as well as in education.
\end{abstract}

\section{Introduction}

The main objective of the paper is to see in specialized literature what are the skills required by Industry 4.0 (I.4.0), what are the means associated with the concept of Education 4.0 (E.4.0) to obtain them, and to what extent education systems are adapting to these new requirements, which are constantly changing. The first introduction presents the Industry 4.0 concept with its advantages and disadvantages, the second chapter deals with the position of human resources in industry 4.0 , followed by a review of the skills required by I.4.0, difficulties that can be encountered in achieving them from the perspective of the basic training of the students as well as due to the fact that we address those from generation Z, elements of E.4.0 that lead to the competencies acquisition and in the last part is presented the current situation from education perspective and also some directions of action, and at the end a number of conclusions focused on what we could do to all benefit from technological progress in industry as well as in education.

In order to achieve the points listed above, a literature review was identified by following the Web of Science database, including the key words Industry 4.0, Education 4.0 and Skills in topic. It was used a boolean operator AND TOPIC: (Industry 4.0) AND

* Corresponding author : ana-maria.feier@upt.ro 
TOPIC: (Education 4.0) and TOPIC: (Skills). The database returned 204 entryes on alltypes. Further, a refinment regarding the open access filter returned a number of 79 papers as 33 Proceedings, 43 articles, 1 early access and 1 editorial material. The other set was found using the same keywords but this time in abstract. This search returned 138 articles, and further using open access filter it returned a number of 58 papers. Combining these two sets (open access and keywords in topic with open access and keywords in abstract) returned a number of 58 papers writed between $2017-2021$.

\section{Industry 4.0 concepts}

In the literature there are a large number of publications that deal with this subject exhaustively. What exactly is Industry 4.0? Industry 4.0 is a strategic initiative of the German government, stated in 2011, to support development of the industrial sector and its technological basis is "smart automation of cyber-physical systems with decentralized control and advanced connectivity", using the potentials of "new technologies and concepts such as IOT, integration of technical processes and business processes in the companies, digital mapping and virtualization of the real world" [1]. The availability and use of the internet and IoT concept and related services enable the creation of networks, communication between manufacturing processes and that way factories became smart environments. [2]

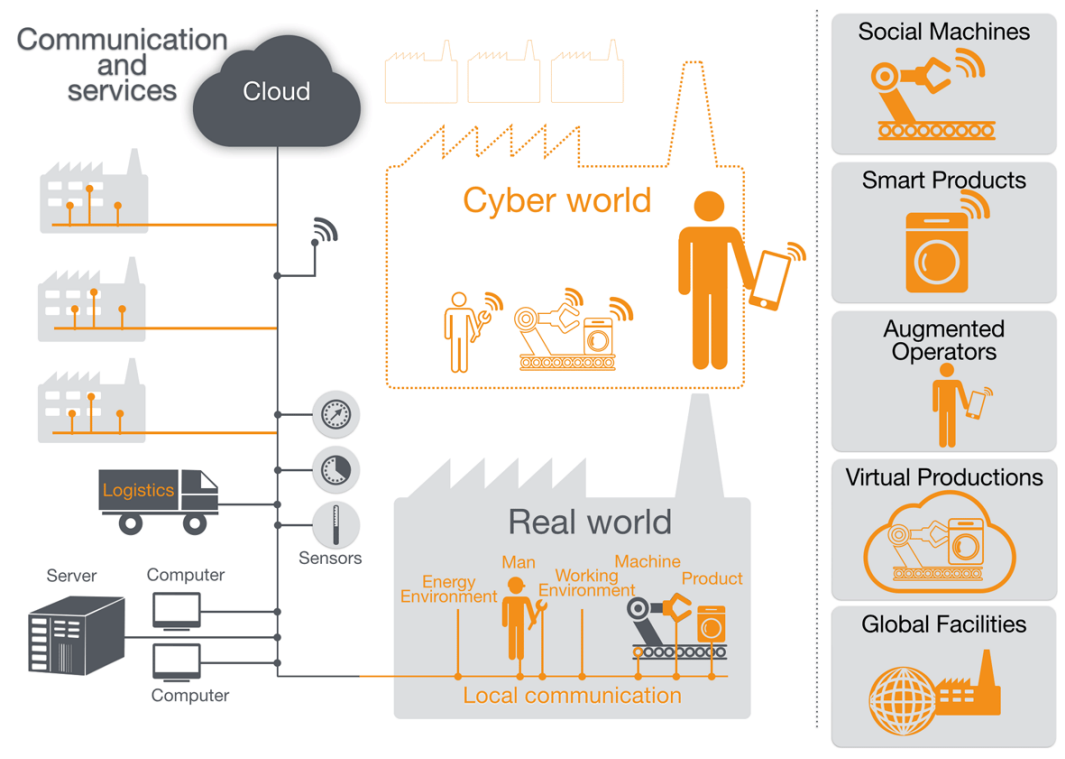

Fig.1. Industry 4.0 [3]

Figure 1 describe the I 4.0 concepts, machines in Industry 4.0 factory are CyberPhysical Systems (self-organizing autonomous systems), physical systems integrated with ICT components, digitization and robotics with their functioning based on AI. CNC and $\mathrm{NC}$ machines are used with mobile agents and robots able of self-organization and selfoptimization [1].

Associated with the concept I.4.0, the Smart notion is addressed in three directions factory, operation area and product and involves the incorporation of digital technologies so that this three exist in a double representation both physical and virtual, elements like 3D models, product versions, when, at what time, on which machines was manufactured a 
product etc., history about data related to the state and parameters of operation of machines etc. - are stored virtually in cloud being able to control, store, process data capture and provide information about your own state of operation as well as interactions with other elements.

Manufacturing systems, products, people and factories must and can be interconnected so that they communicate in real time through applications based on IoT - interoperability and connectivity (ICT, IOT and VR), become essential for Machine-To-Machine interaction (M2M) and Human-To-Machine (H2M) collaboration that is required as production tasks could not be automated [4], [5]. Such an efficient communication system is needed between machines and between machines and operators and therefore advanced user interfaces related to teleoperation and based on AR should be developed.

Among the advantages listed in the literature, without being exhaustively listed here, are mentioned: the shorter path from idea to finished product-thing facilitated by the use of AM techniques, 3D modeling $[6,7]$ and consequently a shorter market time of the products, mass customization [8], ability to anticipate / predict / prevent falls, equipment and maintenance efficiency, ergonomic improvements and less physical effort for the worker that will no longer do routine jobs [9], reconfigurable production systems capable of adapting to different market requirements using soft and hard environments, flexibility in adapting to customer requirements and flexibility in the quantity of products delivered [8]. This also leads to minimal use of resources, materials, and energy because it occurs only when necessary and in the necessary quantity [10].

One drawback is the high costs/investments required by the implementation of I.4.0 and the fact that in terms of integration, digitization and automation all these in order to be implemented require the creation of new means to support them (assumes energy consumption, waste generation) and replaced equipment will have to be stored/recycled with the possibly at least partially to be reused [10].

\section{Human resources and skills in Industry $\mathbf{4 . 0}$}

The design, realization, commissioning then maintenance of CPS, CNC, communication between machines and between machines and people, respectively some work tasks, which can not be fully automated are carried out by engineers and workers who collaborate/communicate with intelligent machines / robots so that an important component are thus the human resources involved in the realization of I.4.0 [6].

Literature leads to the idea of a model in which people and machines work together so it is important to have peoples well trained in digital skills and literacy. [11] at the same time, an environment from which human presence disappears and jobs disappear altogether can lead to social inequity. [5], [12 - 15]. Therefore, the people and skills acquire are the most important resources for innovation and productivity thus ensuring the economic growth, progress and well-being of an entire society.

Very difficult to automate are for example those activities that need detailed knowledge of a process, knowledge based on experience, maintenance of systems require interpretation of the results, installation and control and maintenance of CPS can be done only by highly qualified persons $[5,16]$. The workspaces will be fully virtualized or remotely controllable, which implies collaboration and communication of both $\mathrm{H} 2 \mathrm{H}$ and $\mathrm{H} 2 \mathrm{M}$ and $\mathrm{M} 2 \mathrm{M}$. Engineers are going to be part of hybrid human-robot-teams collaborating with natural user interfaces The human machines interaction and also the complex and multidisciplinary problems that arise and should be solved requires requires new competencies profiles to face this for the 4.0 workers [4].

Even if jobs that can be automated and those having low-level skills disappear, it does not prevent the emergence of new jobs that require high-skill activities like planning, 
control and IT-related tasks necessary for the development, implementation, maintenance and use of new technologies.[16-17], [5].

In this way [18] a key policy and a priority is to adapt educational systems to this reality of the challenges of automation and to provide young people with an education that will take advantage of the benefits of adopting new technologies by providing them with cognitive and social intelligence skills and skills necessary to be able to work as well as specialists as well as users of new digital technologies.

Thus in the context of concept of I.4.0 the organization of work and processes/communication man machine etc. will change following Key Enabling Technologies (KET's) - Technologies underlying Industry 4.0 [19]: Production technologies (Advanced manufacturing technologies, Life science technologies), Digital technologies (Micro/nano electronics and photonics, artificial Intelligence), Cyber technologies (security and connectivity) - hence the need to have the workforce prepared to cope with both the professions that require high qualifications and the existence of specialists in these top fields. There is a need for a well-trained workforce that will need to improve continuously in order to reach higher degrees of employability and competitiveness. However, it is noted the lack of qualified personnel, specialists to face the challenges that the new change brings. An example in this respect, with strict reference to Romania we find in [20]: "64\% of large enterprises and 56\% of SMEs that recruited ICT specialists during 2018, reported that vacancies for ICT specialists are hard to fill/.... in Romania at least $80 \%$ of enterprises that either recruited or tried to recruit ICT specialists reported such difficulties."

Another problem noted [21] by most teachers in STEM disciplines as well as in the automotive industry [19] is the lack of training in STEM area regarding the capacity of gathering the knowledgers for STEM profile that are at KET's understanding and using in order to create, design, innovate, and operated in a high tech environment, $75 \%$ of future jobs will involve STEM knowledge and skills [22, 23, 24].

Action and understanding depend on mastered skills and memory. Complementary, searching, finding, evaluating and communicating information, building knowledge on a particular technical subject matter involves the existence of both cognitive and technical skills and abilities.

In the same context, [25] developed a survey applied to universities and students from EU countries regarding the lack needs and requested competencies and skills on the KETs of the Industry 4.0. They found that robotics and sensors are very familiar, also additive manufacturing (AM) and regarding AM in [6-7] are found similar results. AR and VR are not they being emerging new technologies, cyber-security and communication networks are not familiar from a technical point of view [25].

Numerous authors [26-31], [15] inventory the technical, digital, soft, innovative, management skills table for Industry 4.0. For example, in the paper [28] are inventoried 52 technical skills divided into State of the Art Knowledge Competencies and Skill; IT, Manufacturing, Computer Science and Robotics and Automation Competencies and Skills. They found also 31 non-technical skills of which the most important are problem solving, creativity, decision-making and adaptive skills.

The skills to solve problems, creativity, decision-making and the ability to be flexible and adaptable are often met and stressed as very important so that those workers who have so-called multiple intelligence and who have cross-cultural skills, communication skills, and social, emotional and digital skills will be needed. Looking digital competence/skills they can be obtained by specific education and training, in formal and non-formal systems.

This leads to the idea of a distinction between education and training for employment and education and training for employability which require that the employee have flexibility and a positive attitude towards learning, the desire to learn [33] - the willingness 
and ability to learn, learn, and learn [32] - communication and teamwork offered by education and job-specific skills will be acquired as a result of training $[13,33]$.

However, the ability to be adaptable and be able to learn refers to the changes that new software versions bring, new versions of simulation programs, new features and improvements. The basic technical knowledge is identical but to operate with such efficient and useful programs and to interpret the results requires a thorough training- specialist.

In addition to the listed competencies, consideration should be given to developing the skills and skills of innovation techniques. Associated with the I.4.0 concept is multidisciplinary, both virtual and face-to-face collaboration so that management and transdisciplinary skills are important because we will create value by acquiring these skills by students who will then promote them from the position of employees.

Although innovation skills are needed, which is also pointed out in [19] they are not passed on to students unless in a lesser extent. [34] presents a set of 10 innovation skills examples. Abilities Characteristics (AC), Tehnical or practical (Adaptability Knowledge Troubleshooting); Interpersonal and social (Communication Collaboration Dedication) reasoning (Creativity Proactivity) Management and business (Leadership Analytical thinking).

Managers must also need to face the new model and challenges brought by I.4.0 concept - such as a better ability to communicate with customers in which they are seen as part of the factory, part of the production process, with implications for product customization, IT and production technologies adapted by supply chains [35] and that is why it is necessary to possess new skills in order to support innovative solutions. Also the Industry 4.0 concept require continuous innovation and education that are based on people's competencies /skills and on organizational culture [36].

Top 15 skills according to 2020 WEF [37] are:

- "analytical thinking and innovation";

- "active learning and learning startegies"

- "complex problem solving “

- "critical thinking and analysis"

- "creativity, originality and initiative"

- "leadership and social influence "

- "technology use, monitoring and control"

- "technology design and programming"

- "resilience, stress tolerance and flexibility"

- "reasoning, problem solving and ideation"

- "emotional intelligence"

- "trobleshooting and user experience"

- "service orientation "

- "System analyses and evaluation "

- "Persuasion and negotiation "

Current technological trends, viewed through the light of job dynamics and the change in the importance that some or other of the competences will lead to major curricular changes, it was said in 2016 in [38]: ,More than a third of the desired core skill sets of most occupations will be comprised of skills that are not yet considered crucial to the job today. One question in this regard is what changes have the curricula undergone from 2015 to 2021 to meet the need for additional technological competences with strong social and collaboration skills as seen in 2016?"

Future engineers and the workforce will have to possess these skills. Nevertheless, the way they change, some becoming useless, others that did not exist a few years ago are now in the top 15 and leads us to another question: how could we be so adaptable, thinking through the light of the education system that need to offer these to the future employees? 


\section{To who is the new skills addressed?}

We address several types of "generations" including the so-called netGen or generation Y and generation $\mathrm{Z}$. Generation $\mathrm{Y}$ features are among other the multi-tasking and parallel processing, preference for interactive networked learning rather than individual study, preference for experiential learning activities. The negative aspects are: short attention spans, poor literature and a lack of ability to evaluate the reliability of online content [39].

Members of $Z$ generation are people born from 1995 to 2010, they are digital natives: and they used the internet, the social networks, and the mobile systems every day. Due to this reason the educators must adopt the technology in order to be connected and engaging learning styles of young students to connect with the new. Generation $\mathrm{Z}$ has all the facilities to learn anytime at its own pace and unlimited access to new information but is mentioned again as a disadvantage the lack of attention. The $\mathrm{Z}$ Generation is a digital generation, and new courses in the field of pillars of Industry 4.0 will need to be aligned with the $Z$ generation thinking and skills.

The new digital generation are in direction of I.4.0 concept, therefore requires a thorough and good training of both qualified workers and specialists in terms of technical, digital skills, soft skills, innovative skills and management to cope with the new professions. The need for training does not bypass education systems requiring trained teachers in this subject and that you have a good level of knowledge in these subjects/fields. Looking from this angle - the lack of qualified personnel and of the perspective of training of trainers/teachers still a issue that can raise serious problems [40].

AR and VR will change the education, MOOC and other learning options are available. These days assessment, homework, lectures are online, stored in cloud, work and communication between students and teachers use social media platforms, flexible assignements - all these changes are noticed in real time [41].

The existence of specialized courses, technical support, resources equipment/software/hardware/ are vital, as well as adequate guidance in the learning process. It is very important that universities have teaching staff ready to use and then be able to guide/teach students.

Given the complexity of smart products - which are both finished products as well as machines, equipment, installations, CPS, robots etc. necessary for the operation of I.4.0 it is necessary that future engineers have knowledge from different fields, it is not sufficient, for example, to know and design exclusively the mechanical part but must be able to provide and operate with information from related fields such as IoT, electronics, mechatronics, etc.

\section{Education 4.0 concepts and tools}

The speed of technological advancement and the new technologies causes rapid changes in both the dynamics of competences and the workplace, which leads to the need to rethink creatively the teaching /learning / evaluation process to address some of mentioned problems and in the same time to maintain an adequated level of teaching /learning / evaluation/ assessment objectives and mission of HE.

In the context of digitization, use of AM, AR, VR, IOT, CPS, smart sensors, big data, cyber security etc. successfully in the business sector and contributing to economic and social development, education systems must provide qualified engineers and workers who can both use and design/maintain such complex systems. It is obvious that traditional education systems must take advantage and be updated using innovative teaching/learning 
techniques that use these new technologies. Also innovative technologies such as IoT, CT, AR, VR, cyber security, connectivity, etc. forces the teacher / trainer to keep self-updated with the new entered technologies and in this way he or she should gain new competencies related to the digital information, equipment, technology, and personnel. The framework of Education 4.0 requires a new design of traditional courses, traditional manufacturing factories that add digital technologies [42].

In [43] are analysed 23 master programs with regard to FoF (Factory of the Future) in Romania and found that even there are all had at least two courses addressing conceptual engineering activities, in this moment there is a lack of interdisciplinarity design topics in master programs in Romania.

Education 4.0 will combine real and virtual information [44]. In addition, virtual learning environments (VLE) have already been used to transfer knowledge and skills as well as virtual resources - for example, virtual reality headsets — are used for teaching [4]. Pedagogy could be improved using technology, the transformations with this respect, are needed but still there is a lack of clear instructions on how to proceed furher [17].

The Education 4.0 concept does not change the old structure but adapts it to everyday realities and improves it as content and performance by flexibly and less conventionally integrating existing software applications and learning methods, which have emerged as one-time solutions, of which we exemplify with the following:

\subsection{Education 4.0 tools/approaches inventoried in literature review}

Massively Open Online Course (MOOC) and ICT - they have a big role in the actual and future education, E-learning and E-training. Digital technologies in education changes the learning model, distance learning, e-books, easy to access digital applications. It is obvious that traditional systems will no longer exist, it has to adopt and adapt to digitlisation [17].

- Use of immersive VR in learning sciences reviewed the digital transformations of teachers, students and social context [45].

- The simulation game (learning by doing) is recognized as a powerful tool in education, being better than problem-based learning, students are motivated to maximize their score by trying alternative strategies focusing on interest parameters, reading more literature. In addition, one can learn and "play" in his place, and students play and learn without waiting the teacher to solve them or to show them how to passs a [45-49].

- Video conferencing and simulation emerge as the two most commonly adopted practices in Education 4.0 [48];

- Makerspace environment [50] in this approach is emphasiased the connection between universities and industry, the goal is to fill the gap with professors, researchers, makers, start-ups, and companies who want to use business-to-business practices.

- DesignLab - a dedicated space for doing design in multidisciplinary teams working together on ideation/concept, prototyping and exhibitiong [51].

- AR use of augmented-reality glasses to see dispatch information and navigation instructions, including the exact location of an item, on a shelf, and automatically scanning a barcode, remote assistance with a basic type of maintenance [52].

- VR - simulators used to understand concepts, train and test operation skill, minimizing risks because the trainee/student is not exposed to a real situation - only to a real simulation, failure are costless, the operation can be done multiple times without consumption of raw materials, the possibilities to apply and follow steps on a standardized and optimised procedure [52-54].

- Learning factories, based on didactic, integrative and engineering pillars -a highly complex learning environments that enable the development of theoretical and practical knowledge in a real production environment, development of high quality and autonomous 
skills, and that are linked to training, education, and the development of learning for Industry 4.0 [53, 55-57].

- The teaching factory paradigms - is integrating industry and universities in a place where experts and entry level /future engineers collaborate [16, 42, 58].

- $\quad$ Project Based Learning approach provide a learning experience integrating teoretical and technical knowledge with colllaborative work practices, this characteristics allow students to interact with problems related to the professional context, promoting interdisciplinarity. It facilitates the development of I 4.0 skills and competences. [50, 59$60]$.

\section{Conclusions}

While not a few or simple, the demands of employers at the related of the world economy are well outlined. Human resources specialists know, at some point, exactly for whom and what kind of competences and skills they are looking for. This flexibility of employers' requirements is in fact rapidly adaptable and is caused by the speed at which new technologies manage to meet the requirements of the product market and therefore rapidly depreciating the content of knowledge, competences, skils and qualifications. The question of the criteria for assessing the degree of compliance with the requirements and in particular the minimum admissibility limits is, however, one that remains open and therefore the objectivity of a possible ranking of several candidates in the same job can be questioned.

Manufacturers - in general and those in zone I.4.0 in particular - often direct generators but also direct users of the most advanced technologies, require workers prepared for immediate solving of new tasks. Often, by not finding them in the labour market, they need to be satisfied with new staff who, although they do not possess the required level skills, have a greater willingness to learn and do this faster as their basic knowledge can form a solid foundation for new acquirements directly in the workplace - they learn by doing, sometimes even as new technology is being put into practice or developing. It is well known to those in the productive area that new solutions arise when seemingly insurmountable problems arise - this is actually the "self-combustion engine" that leads to the development of new knowledge or/and the integration of existing ones in a way that has never been thought of before: AM, IoT, AR, VR, CPS, etc.

Concept I.4.0 is, as it results from those presented in introduction, the work of theorists who have put "together" what the industry already uses in its most advanced sectors. Therefore, it is not a "theory" that can be learned, it is rather an "outline" with state-of-theart technique and technology that can be used by integrating components in order to solve existing or predicted situations. Continuous productive practice tends to advance theoretical knowledge and the gap becomes more pronounced.

E.4.0 is also a concept, of the same nature as I.4.0 but after the latter, which appeared precisely to counteract the phase shift noticed earlier. This is all the more difficult as E.4.0 is not a concept that develops independently, first of all E. 4.0 "serve" the I.4.0 concept and only then generate its own targets, the achievement of which becomes sources for innovation or at least modernization of future manufacturing.

The multitude of subjects found in theory and as separate disciplines in the education system with which I 4.0 operates corresponding to each pillar is overwhelming and qualified specialists and workers with technical skills, soft skills and vast knowledge and from other field so called interdisciplinary competencies are needed. At the same time new products and technologies, thinking in relation to KEt's require very well trained people who are able to use them. 
At this moment in most of its part, engineering courses have as applications laboratories/seminars or projects but these are exploring only a small part of design or manufacturing. Working only on one discipline, without expanding and making connections with other disciplines and without seeing the whole leads to the lack of an overview of the problems and the expansion that a subject/project can actually have, which the author in developing teaching process also notes. Even if the emphasis is, at least declaratively on interdisciplinaryity and collaboration it does not take place at a level that ensures that holistic view of all system.

Therefore, interdisciplinaryity must also be found in education, even as a priority, working in interdisciplinary teams. There should be spaces for a single interdisciplinary project and not every subject with its project. In order to meet the requirements of the E.4.0 concept, the projects for completion of studies should be complex projects that go through the stages of product development /conceptual/constructive design / detailed / product engineering / simulation using also mechatronic elements, sensors, 3D printing, VR AR, IoT etc.

Only a close collaboration between universities and industry will contribute to the training of specialists who can work / design / design in environment 4.0. A real integration in which students can have practical experience of working in a factory 4.0 is very important [16]. And if we think about the fact that the school does not possess such a factory in which students practice and be trained in real time, then we can only be skeptical about the transition from theory to practice in the implementation of I4.0 concepts.

Regarding the requirement that new employees have only a technical basis, the soft skills being being more important, the following questions arise:

- At what level of training is it necessary for employees to have soft skills and the ability to learn rather than be specialists?

- What are universities preparing, operators or specialists?

If companies want a basic technical training and an important component of team collaboration, flexibility, rapid adaptation to changing environment, the ability to learn rather than that of knowing already this should change, the extent of the materials that offer training in soft skills.

This way we will be closer to a future employee who is easily learned and who will learn easily. However, not having certain standards for this type of approach, the idea of future research to see the level of software skills required and by what kind of subjects, means, etc. can be achieved, it is necessary.

A learning system cannot be replaced overnight, results are expected in at least one complete cycle of learning and it is usually necessary for an entire generation to go through a system, constantly, without changes in order to be able to conclude on the effectiveness of the strategies adopted. In these conditions, it is clear that in order to keep up with I 4.0 we must immediately start the necessary changes, to increase the degree of adaptability and flexibility to the novelties that the I.4.0 concept promotes.

As a first step towards achieving the objectives of the E.4.0 concept, it is necessary a deep modernization of laboratories, intensive specialization of teachers, a massive and rapid flow of specialists who act according from I.4.0 to E.4.0 and necessarily and vice versa. Therefore, to operate such education is required trong political will, legislation and support consistent massive allocations of human, financial and material quality.

As a general conclusion of the paper, in the future more detailed studies are needed, made by a survey at both level students and industry. The survey will follow the gap between supply and demand in terms of the university - economic environment and the alignment of the curricula to the wishes of Industry 4.0 and to the need of the economic environment. 


\section{References}

1. A. Rojko, Industry 4.0 concept: Background and overview. International Journal of Interactive Mobile Technologies, 11(5), 77-90. https://doi.org/10.3991/ijim.v11i5.7072, (2017)

2. M. Liu, Ma, J., Lin, L., Ge, M., Wang, Q., Liu, C. Intelligent assembly system for mechanical products and key technology based on internet of things. Journal of Intelligent Manufacturing, 28(2), 271-299. https://doi.org/10.1007/s10845-014-0976-6, (2017)

3. Understanding Industry 4.0, available at ottomotors.com, 20 june 2018 , Accessed 20.02 .2021

4. A.Richert, M.Shehadeh, F.Willicks, S. Jeschke, Digital Transformation of Engineering Education - Empirical Insights from Virtual Worlds and Human-Robot-Collaboration. International Journal of Engineering Pedagogy (IJEP), 6(4), 23. https://doi.org/10.3991/ijep.v6i4.6023, (2016)

5. B. Dworschak, H. Zaiser, Competences for cyber-physical systems in manufacturing-First findings and scenarios. Procedia CIRP, 25(C), 345-350. https://doi.org/10.1016/j.procir.2014.10.048, (2014)

6. B. Motyl, S. Filippi, Trends in engineering education for additive manufacturing in the industry 4.0 era: a systematic literature review. International Journal on Interactive Design and Manufacturing. https://doi.org/10.1007/s12008-020-00733-1, (2020)

7. B. Motyl, G. Baronio, S. Uberti, D. Speranza, S. Filippi, How will Change the Future Engineers' Skills in the Industry 4.0 Framework? A Questionnaire Survey. Procedia Manufacturing, 11, 1501-1509. https://doi.org/10.1016/j.promfg.2017.07.282, (2017)

8. How can Industry 4.0 benefit my bussiness ? , BDC's report Industry 4.0: The New Industrial Revolution, avaialable at https://www.bdc.ca/en/articles-tools/technology/investtechnology/how-can-industry-benefit-my-business, Accesed 25 january 2021

9. M. D.Di Nardo, D. Forino, T. Murino, The evolution of man-machine interaction: the role of human in Industry 4.0 paradigm. Production and Manufacturing Research, 8(1), 20-34. https://doi.org/10.1080/21693277.2020.1737592, (2020)

10. J. Oláh, N. Aburumman, J. Popp, M. Khan, H. Haddad, N.Kitukutha, Impact of industry 4.0 on environmental sustainability. Sustainability (Switzerland), 12(11). https://doi.org/10.3390/su12114674, (2020)

11. Positive disruption: health and education in a digital age written by the Pathways for Prosperity Commission on Technology and Inclusive Development, BLAJ6993-Positive-DisruptionReport-190613-WEB.pdf, available at https://pathwayscommission.bsg.ox.ac.uk/positivedisruption, Accessed 15.02.2021

12. R. Someshwar, Y. Edan, Givers \& Receivers perceive handover tasks differently: Implications for Human-Robot collaborative system design. ArXiv, February, (2017)

13. S. Jagannathan, S. Ra, R. Maclean, Dominant recent trends impacting on jobs and labor markets - An Overview. International Journal of Training Research, 17(sup1), 1-11. https://doi.org/10.1080/14480220.2019.1641292, (2019)

14. K. Rojko, N. Erman, D. Jelovac, Impacts of the Transformation to Industry 4.0 in the Manufacturing Sector: The Case of the U.S. Organizacija, 53(4), 287-305. https://doi.org/10.2478/orga-2020-0019, (2020)

15. G. B.Cotet, N. L.Carutasu, F. Chiscop, Industry 4.0 diagnosis from an imillennial educational perspective. Education Sciences, 10(1). https://doi.org/10.3390/educsci10010021, (2020)

16. D. A Zakoldaev, A. V Shukalov, Zharinov, I. O., J. V. Grunicheva, Education management to prepare the specialists for the industrial companies Industry 4.0. Journal of Physics: Conference Series, 1333(7). https://doi.org/10.1088/1742-6596/1333/7/072032, (2019)

17. M. Muktiarni, I. Widiaty, A. G Abdullah, A. Ana, C. Yulia, Digitalisation trend in education during industry 4.0. Journal of Physics: Conference Series, 1402(7). https://doi.org/10.1088/1742-6596/1402/7/077070, (2019)

18. OECD Putting faces to the jobs at risk automation, policy brief on the future of work, OECD Publishing, Paris Automation-policy-brief-2018.pdf (oecd.org), (2018)

19. Re-finding Industry Defining Innovation Report of the independent High Level Group on industrial technologies; PDF ISBN 978-92-79-85271-8 doi:10.2777/927953 KI-01-18-408-EN-N (2018) 
20. https://ec.europa.eu/digital-single-market/en/human-capital-and-digital-skills,

Accessed 10.3.2021

21. R.N. Hafni, T. Herman, E. Nurlaelah, L. Mustikasari, The importance of science, technology, engineering, and mathematics (STEM) education to enhance students' critical thinking skill in facing the industry 4.0. Journal of Physics: Conference Series, 1521(4). https://doi.org/10.1088/1742-6596/1521/4/042040, (2020)

22. Australian Industry Group https:/www.aigroup.com.au/policy-andresearch/mediacentre/reports/, (2015), Accesed 14.02.2021

23. Key Challenges for Higher Education in Europe - Annex II: Results of the Public Consultation on the EU's Modernisation Agenda for Higher Education, May (2016)

24. Engineering Education. Research and Development in Curriculum and Instruction, John Heywood, Published by John Wiley \& Sons, Inc., Hoboken, New Jersey, ISBN-13978-0-47174111-4, p. 354, (2005)

25. J. L. Romero Gázquez, M. V.Bueno Delgado, J.J. Ortega Gras, J.Garrido Lova, ,M.V. Gómez Gómez, M. Zbiec, Lack of skills, knowledge and competences in Higher Education about Industry 4.0 in the manufacturing sector. RIED. Revista Iberoamericana de Educación a Distancia, 24(1), 285. https://doi.org/10.5944/ried.24.1.27548, (2020)

26. C. Terkowsky, S. Frye, D. May, Online engineering education for manufacturing technology: Is a remote experiment a suitable tool to teach competences for "Working 4.0"? Eur J Educ, 54, 577-590. https://doi.org/10.1111/ejed.12368, (2019)

27. A. Jerman, A. Bertoncelj, G. Dominici, M.Pejić Bach, A. Trnavčević, Conceptual Key Competency Model for Smart Factories in Production Processes. Organizacija, 53(1), 68-79. https://doi.org/10.2478/orga-2020-0005, (2020)

28. I. Janis, A Systematic Literature Review: Human Roles, Competencies And Skills In Industry 4.0. 1052-1072. https://doi.org/10.15405/epsbs.2018.05.84, (2018)

29. Z. A. Mingaleva, N. A. Vukovic, Development of engineering students competencies based on cognitive technologies in conditions of industry 4.0. International Journal of Cognitive Research in Science, Engineering and Education, 8(Special Issue 1), 93-101. https://doi.org/10.23947/2334-8496-2020-8-SI-93-101, (2020)

30. Č. Serafín, Information science in technical education process in Czech Republic. International Journal of Engineering Pedagogy, 9(5), 89-102. https://doi.org/10.3991/ijep.v9i5.11142, (2019)

31. S. Pfeifer, Effects of Industry 4.0 on vocational education and training, Access item:http://epub.oeaw.ac.at/ita/ita-manuscript/ita_15_04.pdfISSN: 1681-9187, Vienna, November (2015)

32. Sungsup Ra, Unika Shrestha, Sameer Khatiwada, Seung Won Yoon, Kibum Kwon, The rise of technology and impact on skills, International Journal of Training Research, 17:sup1, 2640, DOI: 10.1080/14480220.2019.1629727), (2019)

33. V. Siddoo, J. Sawattawee, W. Janchai, O. Thinnukool, An exploratory study of digital workforce competency in Thailand. Heliyon, 5(5). https://doi.org/10.1016/j.heliyon.2019.e01723, (2019)

34. F. M. La Rivera, P. Hermosilla, J. Delgadillo, D. Echeverría, The sustainable development goals (SDGs) as a basis for innovation skills for engineers in the industry 4.0 context. Sustainability (Switzerland), 12(16). https://doi.org/10.3390/su12166622, (2020)

35. Carles Roig, Industry 4.0. New forms of intelligence, knowledge and management skills; available at https://dobetter.esade.edu/en/industry-4.0, accessed 5.03.2021

36. H. Mohelska, M. Sokolova, Management approaches for industry $4.0-$ The organizational culture perspective. Technological and Economic Development of Economy, 24(6), 2225-2240. https://doi.org/10.3846/tede.2018.6397, (2018)

37. The Future of Jobs Report 2020 OCTOBER 2020 available at https://www.weforum.org/reports/the-future-of-jobs-report-2020, Accessed 10.02.2021

38. The Future of Jobs Employment, Skills and Workforce Strategy for the Fourth Industrial Revolution January 2016 avaiable at http://www3.weforum.org/docs/WEF_FOJ Executive_Summary Jobs.pdf 2016, accessed 10.02 .2021

39. D. G. Oblinger, J. L. Oblinger, Educating the Net Generation, Available electronically at www.educause.edu/educatingthenetgen/, ISBN ISBN 0-9672853-2-1, (2005) 
40. S. H. Mian, B. Salah, W. Ameen, K. Moiduddin, H. Alkhalefah, Adapting universities for sustainability education in industry 4.0: Channel of challenges and opportunities. Sustainability (Switzerland), 12(15). https://doi.org/10.3390/su12156100, (2020)

41. A. H. Anaelka, Education 4.0 Made Simple: Ideas For Teaching. International Journal of $\begin{array}{lllll}\text { Education and } & \text { Literacy } & \text { Studies, } & 6(3), & 92 .\end{array}$ https://journals.aiac.org.au/index.php/IJELS/article/view/4616, (2018)

42. D.Mourtzis, E.Vlachou, G. Dimitrakopoulos, V. Zogopoulos, Cyber- Physical Systems and Education 4.0 -The Teaching Factory 4.0 Concept. Procedia Manufacturing, 23, 129-134. https://doi.org/10.1016/j.promfg.2018.04.005, (2018)

43. A. Florea, Digital Design Skills for Factories of the Future. MATEC Web of Conferences, 290, 14002. https://doi.org/10.1051/matecconf/201929014002, (2019)

44. A. Benesova, J. Tupa, Requirements for education and qualification of people in Industry 4.0. Procedia Manufacturing, 11, pp. 2195-2202, (2017)

45. Richert et al., "Learning 4.0. Virtual immersive engineering in Digital Universities: International Best Practices education", and Applications, 2/2015

46. M.J. Mayo, Games for science and engineering education. Communications of the ACM, 50(7), 30-35. https://doi.org/10.1145/1272516.1272536, (2007)

47. A. A.Deshpande, S.H. Huang, Simulation games in engineering education: A state-of-the-art review. Computer Applications in Engineering Education, 19(3), 399-410. https://doi.org/10.1002/cae.20323, (2011)

48. F. Almeida, F., \& Simoes, J. (2019). The role of serious games, gamification and industry 4.0 tools in the education 4.0 paradigm. Contemporary Educational Technology, 10(2), 120-136. https://doi.org/10.30935/cet.554469

49. BIBA - Research for Production and Logistics, https://www.biba-gaminglab.com/en/about-thebiba/, Accessed 20 february 2021

50. E. F.Dos Santos, P. Benneworth, Makerspace for skills development in the industry 4.0 era. Brazilian Journal of Operations \& Production Management, 16(2), 303-315.

https://doi.org/10.14488/bjopm.2019.v16.n2.a11, (2019)

51. I. D. Engineering, DESIGNLAB , MAKING SPACE FOR DOING DESIGN. September, 3-8, (2015)

52. M.Butter, DIRECTORATE GENERAL FOR INTERNAL POLICIES POLICY DEPARTMENT A: ECONOMIC AND SCIENTIFIC POLICY Horizon 2020: Key Enabling Technologies (KETS), Booster for European Leadership in the Manufacturing Sector STUDY, (2014)

53. B.Salah, M. H.Abidi, S. H.Mian, M. Krid, H.Alkhalefah, A. Abdo, Virtual reality-based engineering education to enhance manufacturing sustainability in industry 4.0. Sustainability (Switzerland), 11(5). https://doi.org/10.3390/su11051477, (2019)

54. A. Feier, F.Banciu, ERGONOMIC ASPECTS OF REAL AND VIRTUAL WELDING TOOLS, in Acta Tehnica Napocensis/Series Applied mathematics, mechanics and Engineering, vol.64, No.1-S1 https:/atnamam.utcluj.ro/index.php/Acta/article/view/1502, (2021)

55. R. G. Souza, O. Quelhas, G. Marchisotti, J. Neto, R. Anholon, C. A.Marinho, Production engineering curriculum in industry 4.0 in a brazilian context. South African Journal of Industrial Engineering, 31(4), 136-150. https://doi.org/10.7166/31-4-2033, (2020)

56. F. Baena, A. Guarin, J. Mora, J. Sauza, S. Retat, Learning Factory: The Path to Industry 4.0. Procedia Manufacturing, 9, 73-80. https://doi.org/10.1016/j.promfg.2017.04.022, (2017)

57. C. Alves, G. Putnik, Experiential learning of CAD systems interoperability in social networkbased education. Procedia CIRP, 84, 209-214. https://doi.org/10.1016/j.procir.2019.07.002, (2019)

58. G. Chryssolourisa, D. Mavrikiosa, L. Rentzos, The Teaching Factory: A Manufacturing Education Paradigm Procedia CIRP 57 ( 2016 ) 44 - 48, 49th CIRP Conference on Manufacturing Systems (CIRP-CMS 2016)

59. C. Vila, D.Ugarte, J. Ríos, J. V. Abellán, Project-based collaborative engineering learning to develop Industry 4.0 skills within a PLM framework. Procedia Manufacturing, 13, 1269-1276. https://doi.org/10.1016/j.promfg.2017.09.050, (2017)

60. N. A. Bushmeleva, N. I. Isupova, E. A. Mamaeva, E. V. Kharunzheva, Peculiarities of 
engineering thinking formation using 3D technology. European Journal of Contemporary Education, 9(3), 529-545. https://doi.org/10.13187/ejced.2020.3.529, (2020) 